in which an experiment on his own person was only prevented from proving fatal by timely swallowing of his shaving water, was a significant indication of the thoroughgoing spirit in which all his researches were pursued. As a pharmacien he rendered valuable service to the profession in connection with the last edition of the "Edinburgh Pharmacopœia," merged since 1864, like those of London and Dublin, in the "Pharmacopoeia Britannica," prepared under the auspices of the General Medical Council ; and in his "Dispensatory," published in 1842 (second edition, 1848 ), he presented a commentary on the then existing Pharmacopoias, characterised, like his book on Poisons, by precision in details, and by the concise, yet happy expression of suggestive gereralisations.

In the professorial chair Dr. Christison proved a singularly lucid and instructive lecturer. Himself strictly methodical in everything pertaining to scientific inquiry or professional routine, he fostered in his students habits of exact and well-regulated work. As the result of his incumbency, both the chairs he occupied gained no inconsiderable accession of usefulness and importance while to that of Materia Medica he left a substantial legacy in the splendid museum, whose riches can never be appreciated till it is properly displayed in the new Medical School. By his students he was loved as well as admired; and once and again, in the course of his long career, old pupils scattered far and wide as busy practitioners, have shown themselves prompt to embrace every opportunity of doing him honour.

As a member of the Senatus Academicus, and Assessor for that body in the University Court-an office to which he was elected five times in succession-Prof. Christison took an active and prominent part in the management of college affairs. No member of the University was more energetic in pushing forward that great scheme of extension which, as now all but realised in a new Medical School, alongside of the new Infirmary, will doubtless raise Edinburgh to a yet higher position as a seat of medical education. The movement for better endowment of the University also found a warm supporter in one who was ever ready to advance what he believed to be the true interests of learning. An ardent lover of all manly exercises, the doctor was himself noted, in his youth, as the most accomplished athlete in the University. A story is told of his having, on one occasion, accomplished the rarely equalled feat of running from the College gate to the top of Arthur seat within twenty-five minutes. In after years, athleticism would often form part of the diversions with which the Professor and his friends relieved the cares of professional life. Even as an octogenarian the vivacious Professor continued to be remarked for the almost jaunty elasticity of his step.

By the Edinburgh Medical Faculty his eminence was duly recognised in his election on two distinct occasions - in 1838 , and again in 1846 --to the presidentship of the Royal College of Physicians, an honour which was fitly followed up by the Fellows according a place in their hall to his portrait by Sir John Watson Gordon. On the death of Sir David Brewster, he was elected president of the Edinburgh Royal Society; and in this office, held from 1868 to 1873 , as well as in the vice-presidentship, which he had formerly filled, he acquitted himself with a distinction which the Society acknowledged by adding his portrait to their gallery of illustrious men. Assiduous in his attendance at the Society's meetings, Dr. Christison from time to time contributed papers to the Transactions. Among the subjects thus discussed may be mentioned that of fossil plants in the coal formation, and the remains of ancient trees found in Craigleith and other quarries, on the study of which he brought to bear the resources of chemical analysis. In 1857 Dr. Christison's position among Scotch physicians was fitly recognised in his being nominated by the Crown to represent the profession in Scotland at the General Medical Council. After having for many years held the honorary office of a Physician in Ordinary to the Queen for Scotland, Prof. Christison in I 87 I was created a baronet of the United Kingdom, a distinction which was conferred on the recommendation of the then Prime Minister, Mr. Gladstone. In I873 he celebrated the jubilee of his professorship, an occasion of which friends and admirers were eager to take advantage for testifying their appreciation of the veteran physician. In 1875 he presided over the Edinburgh meeting of the British Medical Association. The veteran's general standing as a scientific man was no less unmistakably certified in his being selected, in 1876 , for the presidentship of the British Association for the Advancement of Science: though this honour, in deference to the advice of friends, who feared the effort might overtax his strength, he felt constrained to decline. It was not many months later that an illness, by which he was for a time completely prostrated, led to his resignation of professorial duty.

Sir Robert Christison was married in 1827 to Henrietta Sophia, daughter of Mr. David Brown, of Greenknowe, Stirlingshire. Mrs. Christison died in 1849 ; but there survive three sons, of whom Alexander, the eldest, born in 1828 , was educated at the Edinburgh Academy and High School, and after serving in various capacities, is now Deputy Surgeon-General of the Bengal Army.

\section{CONCERNING THE GAS-FLAME, ELECTRIC, AND SOLAR SPECTRA, AND THETK EFFECTS ON THE EYE}

THE spectra of the light from these various sources is a subject to which I gave some attention about two years ago, and a detailed account of my experiments may be found in the Proceedings. of the American Academy of Sciences for 1880 , p. 236 . In this article it was shown that the colour of the sun was not what the-average person would call white, but decidedly bluish. The sun's "golden glare" spoken of by Mr. Capron is entirely a subjective effect (except when near the horizon); and foliows from the well-known law that bright lights tend to look yellow, and faint on es blue. If the highly magnified images of two diaphragms equally illuminated, one by the electric light and one by the sun, be cast upon a screen, the distinctly bluish character of the latter will be strongly marked. Indeed, the magnesium light is more blue than the electric, and hence probably is of a higher temperature, although being spread through a larger space, has less available heating power. As far as mere colour is concerned then, the electric light approaches nearer to the sun than does the gas-flame.

From subsequent experiments, however, it is my impression that colour has nothing whatever to do with the painful effects sometimes noticed in the eyes, after long and continuous work by artificial light. To test this question, I had a tin lamp-shade constructed, consisting of a tube six inches in diameter by eight in length. One end was closed by a reflector, and the other by a piece of very light blue glass. Two holes were made in the sides, through which passed the glass chimney of an Argand gas-burner. By experimenting with a shadow photometer, a position was found where the light received on a book was of the same intensity, and very similar colour, to that from a window in the daytime, at a distance of about six feet. A few minutes' reading, however, was sufficient to convince me that the new light was far more trying to the eyes than an ordinary gas-flame would be. The illeffects being due to the intense heat thrown down by the reflector. And this I think is the source of the whole trouble in the ordinary gas-burner. The heat radiated by the flame, the heated chimney and shade, and reflected 
from the printed page, and all other white paper lying on the table, dries the eyes, the lids, the forehead, and temples, Temporary relief may be found by bathing the face and eyes in water, but it is only temporary. The hot, dry air about the lamp is also harmful, and no doubt contributes its share of injury to the vision. These evils may both in part be remedied by placing a pane of glass so as to intercept the rays from the lamp before they strike on the book or the face. But it must be placed at such a distance from the lamp as not itself to become heated.

The hotter the flame, the whiter it is, and the more light is thrown off in proportion to the heat. Hence oculists are recommending such lights as the Student's and Moderator lamps, which burn with a small, hot, and very brilliant flame, as compared with that furnished by the Argand and fish-tail burners. We learn from statistics how alarmingly prevalent near-sightedness has become of late among students. Hence anything which will tend in the future to prevent this wide-spread defect will be boon to mankind. And here is where the particular advantages of electricity come to the front. The fact that there are no gaseous products to radiate heat without light, taken together with the high temperature of the incandescent carbon, unite to give us the maximum of light with the minimum of heat. The evcr-varying intensity of the arc light is at present a strong objection to it, but we may look forward to the success of the light from the incandescent carbon strip, in the near future, with the assurance that we shall soon have a remedy for the most wide-spread evil that afflicts the human vision.

Boston, Mass., U.S.A.
W. H. PICKERING

\section{THE GREAT NEBULA IN ANDROMEDA}

$\mathrm{F}^{\mathrm{EW}}$ objects in the heaven save been treated with such unmerited neglect as this which has not inaptly been termed the Queen of the Nebulæ. Notwithstanding its enormous magnitude, spreading out, as followed by the Harvard I5-inch achromatic, to $24^{1}$ in length, (according to Bond-Trouvelot gives more), with a breadth of upwards of $I^{\circ}$; and its conspicuous brightness, readily perceptible with the naked eye, it has received little com.

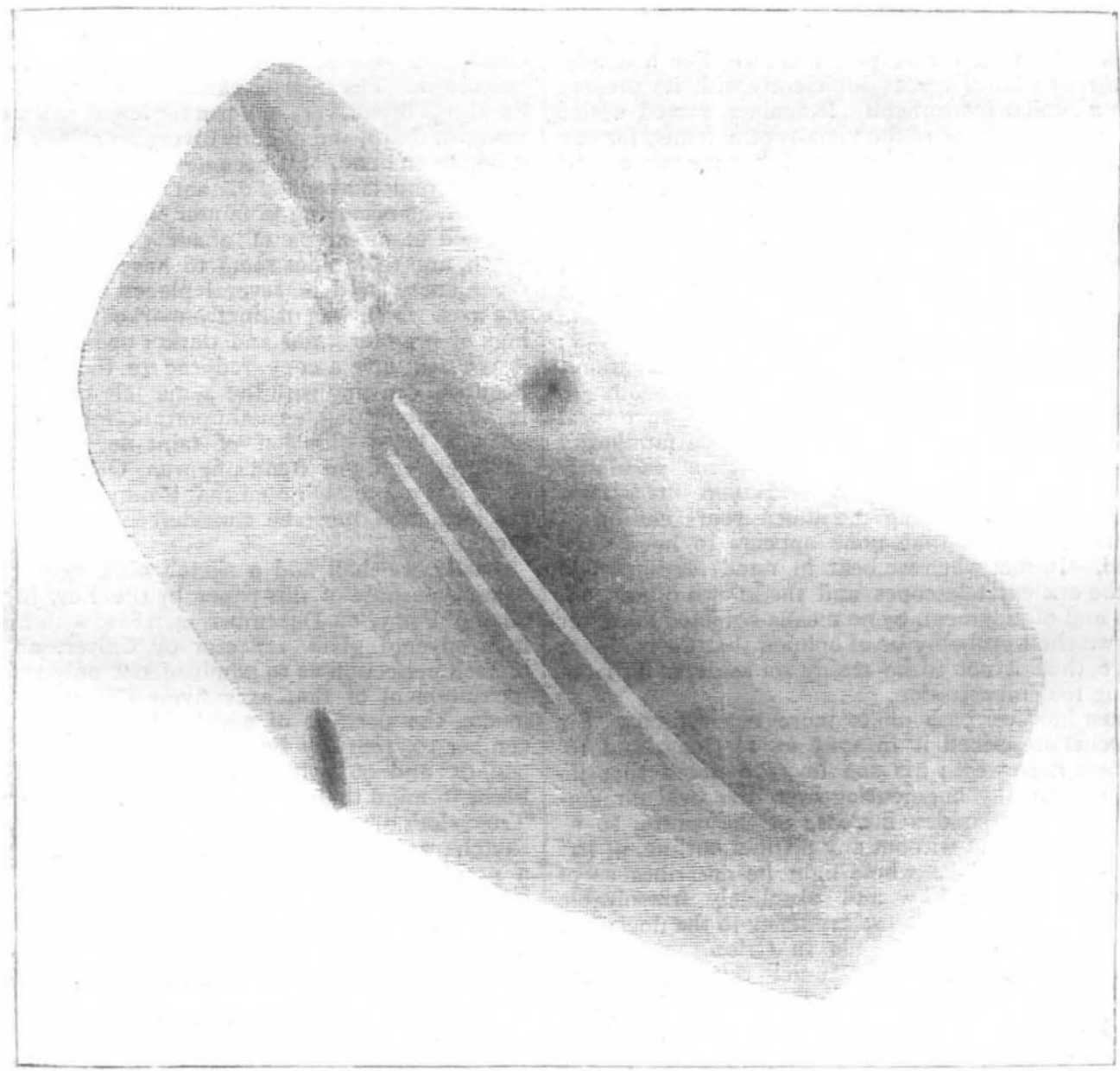

FIG. I. - Bond, 1847 .

parative notice. The reason probably may be the pertinacity with which it has hitherto resisted all inquiry, and defied the efforts of the most powerfully armed investigation; so that it seems to have been left on one side, as too unpromising for more than casual inspection.
This however bears the character of a premature conclusion. Direct examination by the most powerful telescopes has done very little to solve the mystery of its nature. The reply extorted by the spectroscope is but partially intelligible. But we must not therefore despond. 